\title{
FACIAL SWELLING IN GIANT CELL (TEMPORAL) ARTERITIS
}

\author{
FARUQUE D. GHANCHI, CLIFFORD WEIR and JOHN DUDGEON \\ Glasgow
}

\begin{abstract}
SUMMARY
Giant cell (temporal) arteritis is a systemic vasculitis of the elderly. Facial swelling is a rare manifestation of the arteritic process. Delay in recognition of the condition can result in profound loss of vision. This report describes a biopsy-proven arteritic patient who developed anterior ischaemic optic neuropathy (AION) following facial swelling. Both arteritic AION and facial swelling responded to high-dose steroid treatment. Facial swelling in giant cell (temporal) arteritis could be an indicator of risk of AION. Intravenous steroid treatment can lead to salvation of useful vision.
\end{abstract}

Giant cell (temporal) arteritis (GCA) is a systemic vasculitis of the elderly which commonly affects arteries of the head and neck. ${ }^{1}$ The usual systemic features of the disease include headache, scalp (temporal) tenderness, jaw claudication, malaise and arthralgia in proximal joints. The disease frequently leads to ischaemic optic neuropathy, which usually is irreversible. ${ }^{2}$ A prompt diagnosis of GCA and treatment with high doses of steroids is essential to prevent further visual loss. ${ }^{2}$ When the classical features of GCA are present, diagnosis of the condition is not difficult. Atypical presentation of GCA is fortunately rare. A patient is described here who presented with anterior ischaemic optic neuropathy (AION) and a history of facial swelling, whose visual acuity improved following steroid treatment.

\section{CASE REPORT}

A 79-year-old Caucasian woman presented with complaints of sudden, painless blurring of vision in her left eye, noticed on waking, a day before presentation. Her other symptoms included shoulder pains, malaise and tiredness but no headache, fever or weight loss. There was no tongue claudication or tinnitus but the patient described a 'heavy' feeling on

Correspondence to: Dr Faruque D. Ghanchi, MS, FRCOphth, Tennent Institute of Ophthalmology, Church Street, Glasgow G11 6NT, UK. Fax: +44 (0141) 3397485. the affected side of the face. Interestingly, the patient had suffered swelling of the face on the left side and around the left eye a month prior to presentation, which was attributed to an 'allergic' reaction. The facial swelling was associated with pain on chewing, which settled with simple analgesia, without any sequel. Apart from poorly controlled hypertension, there was no history of other systemic disorders.

On examination, her best corrected visual acuity was 6/9 (OD) and hand movements (OS). An afferent pupillary defect in the left eye was recorded. Both anterior segments were normal, with normal intraocular pressure. Fundus examination showed posterior vitreous detachment in both eyes. There was pallid swelling of the left optic disc with a small flame haemorrhage superior to the fovea. The optic disc in the right eye appeared well perfused. The retinal vasculature in both eyes was normal and free of any thrombus or embolus.

The erythrocyte sedimentation rate (ESR) in clinic was $94 \mathrm{~mm}$ in the first hour. Both temporal arteries were non-tender and pulsatile. There was no carotid bruit on auscultation but an ejection systolic murmur in the aortic area was recorded. Blood pressure was $182 / 92 \mathrm{mmHg}$. Though the patient and her relative had noted left-sided facial swelling prior to her presentation, none was evident on admission.

A diagnosis of arteritic AION was made. Following an intravenous injection of $500 \mathrm{mg}$ hydrocortisone, the patient was admitted for further management with $80 \mathrm{mg}$ prednisolone orally. Five hours later, her visual acuity in the left eye improved to $6 / 24$. The diagnosis of GCA was further supported by raised levels of C-reactive protein and alkaline phosphatase. The left temporal artery was noted to be thickened at biopsy, histology of which confirmed the diagnosis of GCA.

The patient's visual acuity continued to improve gradually with a corresponding fall in ESR with oral prednisolone treatment. However, the visual field of the left eye remained grossly constricted with only a 
small central island allowing good central vision. The patient's sensation of a 'heavy' feeling on the left side of the face and systemic symptoms also subsided. The dose of prednisolone was gradually reduced, and on discharge her visual acuity was $6 / 9$ in both eyes at 1 week. Subsequent clinical examinations recorded an ESR below $17 \mathrm{~mm} /$ hour and a stable visual acuity of 6/9 in both eyes. Visual fields, however, remained unchanged. The left eye had an afferent pupillary defect and pallor of the left optic disc was noticed.

\section{COMMENTS}

This case report highlights an unusual presentation of GCA with facial swelling and an exceptionally favourable response of AION to steroid treatment. Swelling in the temporal fossa is a recognised feature of the disease and, when seen, it is believed to be indicative of arteritis. Facial swelling, however, has been described as a manifestation of GCA only in a handful of cases. ${ }^{3,4}$ Facial swelling may be accompanied by trismus ${ }^{4}$ or glossitis ${ }^{3}$ depending on the vasculature involved in the arteritic process. The present patient had facial swelling associated with jaw claudication a month prior to loss of vision. This was attributed to an 'allergic' reaction and subsided after simple analgesia. Though the patient and her relative reported noticing facial swelling prior to loss of vision, this was not confirmed at admission. Indeed, some patients with GCA report a sensation of facial swelling ${ }^{5,6}$ though clinically no swelling can be detected.

Our patient complained of malaise and shoulder aches but no headache on admission for AION. Though jaw pain was reported at the first episode of facial swelling, GCA was unfortunately not suspected. It may be that the jaw pain was thought to be secondary to 'allergic' facial oedema. One of the two patients reported by Friedman and Friedman ${ }^{5}$ was also treated with antihistaminics for facial swelling. Though rare, facial swelling or a sensation of facial swelling in the elderly should raise the suspicion of GCA, particularly when other symptoms of GCA are present. Appropriate investigations at such a stage can help to establish the diagnosis of GCA and appropriate treatment can help to prevent serious visual complications.

In a review of case records, Friedman and Fried$\operatorname{man}^{5}$ found 13 of 58 biopsy-proven GCA patients with a sensation of facial swelling, all of whom developed visual disturbance. They concluded that the sensation of facial swelling could be a predictor for development of visual disturbance. ${ }^{5}$ AION in our patient was preceded by facial swelling (a month earlier) and was accompanied by a heavy feeling in the face. This probably indicated involvement of both external and internal carotid circulations in the arteritic process at different times. GCA possibly has a variable temporal and spatial course, affecting different vascular trees at random. In the external carotid system, the temporal artery is commonly involved in the arteritic process ${ }^{1}$ and is routinely examined for evidence of GCA. Histological evidence of involvement of the facial artery in the arteritic disease process causing ischaemic claudication of masticatory muscles is reported. ${ }^{7}$ Arteritis of the facial artery probably was responsible for the facial swelling in our patient, who also complained of jaw claudication. In addition, the development of AION following facial swelling suggested subsequent involvement of the posterior ciliary arteries in GCA. Facial swelling or the sensation of facial swelling in GCA should therefore be considered a risk factor for further ischaemic complications including loss of vision.

Visual loss due to arteritic AION is usually permanent and so the aim of treatment is preventive. ${ }^{2}$ Intravenous steroids have been reported to improve visual function in GCA. ${ }^{8-12}$ In one study, intravenous steroid treatment led to an improvement in 9 of 23 patients. ${ }^{13}$ In the case reported, the treatment consisted of an initial intravenous injection of hydrocortisone and subsequent oral prednisolone ( $80 \mathrm{mg}$ ). The patient's central visual acuity improved from hand movements to $6 / 9$ and remained stable. It may be that there is a 'window of opportunity' to reduce tissue oedema in the optic nerve to allow decompression of viable nerve fibres. Such a phenomenon - 'ischaemic penumbra' - is described in neural ischaemia. ${ }^{14}$ Corticosteroids may help reduce such inflammatory oedema and hence improve tissue perfusion in the acute phase of GCA. Once this is achieved, oral steroids can maintain the anti-inflammatory response and prevent further compromise of the circulation. We believe that reduction of tissue oedema in the optic nerve by an initial bolus of steroid preserved the viability of macular fibres in our patient.

In conclusion, facial swelling can be an uncommon presenting feature of GCA which, if unrecognised, can lead to sight-threatening complications. On the basis of a single case report it is impossible to draw firm conclusions, but achieving a high systemic level of corticosteroid early in the evolution of arteritic AION may be helpful in salvaging useful vision. Clinicians should be aware of uncommon manifestations of GCA to allow prompt diagnosis and early treatment, crucial in preventing further ischaemic damage.

Key words: Giant cell (temporal) arteritis, Facial swelling, Anterior ischaemic optic neuropathy (AION), Steroid treatment, Ischaemia.

\section{REFERENCES}

1. Wilkinson IM, Russell RW. Arteries of the head and neck in giant cell arteritis: a pathological study to show 
the pattern of arterial involvement. Arch Neurol 1972;27:378-91.

2. Hayreh SS. Ophthalmic features of giant cell arteritis. Baillieres Clin Rheumatol 1991;5:431-59.

3. Cohen MD, Ginsburg WW, Allen GL. Facial swelling and giant cell arteritis. J Rheumatol 1982;9:325-7.

4. Manganelli P, Malvezzi L, Saginario A. Trismus and facial swelling in a case of temporal arteritis. Clin Exp Rheumatol 1992;10:102-3.

5. Friedman G, Friedman B. The sensation of facial swelling in temporal arteritis: a predictor for the development of visual disturbance. Postgrad Med J 1986;62:1019-20.

6. Fainaru M, Friedman G, Friedman B. Temporal arteritis in Israel: a review of 47 patients. J Rheumatol 1979;6:330-5.

7. Achkar AA, Lie JT, Gabriel SE, Hunder GG. Giant cell arteritis involving the facial artery. J Rheumatol 1995;22:360-2.

8. Model DG. Reversal of blindness in temporal arteritis with methylprednisolone. Lancet 1978;2:340.
9. Rosenfeld SI, Kosmorsky GS, Klingele TG, Burde RM, Cohn EM. Treatment of temporal arteritis with ocular involvement. Am J Med 1986;80:143-5.

10. Diamond JP. Treatable blindness in temporal arteritis. Br J Ophthalmol 1991;75:432.

11. Matzkin DC, Slamovits TL, Sachs R, Burde RM. Visual recovery in two patients after intravenous methylprednisolone treatment of central retinal artery occlusion secondary to giant-cell arteritis. Ophthalmology 1992;99:68-71.

12. Postel EA, Pollock SC. Recovery of vision in a 47-yearold man with fulminant giant cell arteritis. J Clin Neuroophthalmol 1993;13:262-70.

13. Liu GT, Glaser JS, Schatz NJ, Smith JL. Visual morbidity in giant cell arteritis: clinical characteristics and prognosis for vision. Ophthalmology 1994; 101:1779-85.

14. Astrup J, Siesjo BK, Symon L. Thresholds in cerebral ischaemia: the ischaemic penumbra. Stroke 1981; 12:723-5. 